Dicle Tıp Dergisi / Dicle Med J (2019) 46 (4) : 697 - 705

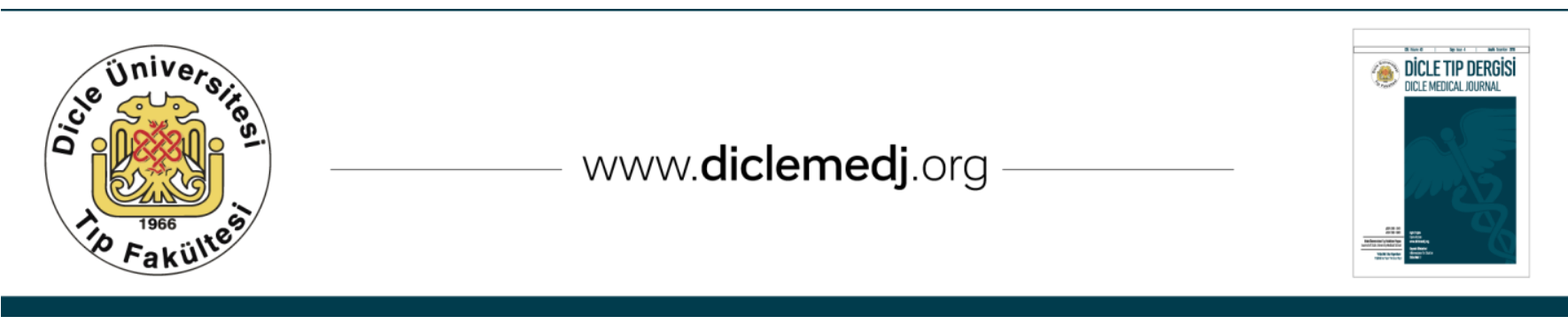

Özgün Araștırma / Original Article

\title{
Akut ve Kronik Pulmoner Tromboembolide Cerrahi Tecrübelerimiz
}

\author{
Mehmet Işı1k ${ }^{1}$ Ömer Tanyeli², Yüksel Dereli³ ${ }^{3}$ Erdal Ege ${ }^{4}$, Niyazi Görmüş̧5 \\ 1 Necmettin Erbakan Üniversitesi Meram Tıp Fakültesi Kalp ve Damar Cerrahisi ABD. Konya, Türkiye ORCID: 0000-0002-2154-7473 \\ 2 Necmettin Erbakan Üniversitesi Meram Tıp Fakültesi Kalp ve Damar Cerrahisi ABD. Konya, Türkiye ORCID: 0000-0001-6275-7744 \\ 3 Necmettin Erbakan Üniversitesi Meram Tıp Fakültesi Kalp ve Damar Cerrahisi ABD. Konya, Türkiye ORCID: 0000-0002-3794-1045 \\ 4 Necmettin Erbakan Üniversitesi Meram Tip Fakültesi Kalp ve Damar Cerrahisi ABD. Konya, Türkiye ORCID: 0000-0002-6192-4915 \\ 5 Necmettin Erbakan Üniversitesi Meram Tıp Fakültesi Kalp ve Damar Cerrahisi ABD. Konya, Türkiye ORCID: 0000-0002-8264-3653 \\ Geliş: 03.05.2019; Revizyon: 01.11.2019; Kabul Tarihi: 04.11.2019
}

Öz

Giriş-Amaç: Pulmoner emboli vakaları tedavi edilmediği takdirde ani ölüm, hayatı tehdit eden akut bir durum ya da trombüslerin pulmoner damar duvarında organize olmasına bağlı olarak kronik tromboembolik pulmoner hipertansiyon gelişir. Bu çalışmada, tüm dünyada belirli merkezler dışında çok fazla sayıda yapılmayan ve mortalitesi yüksek olan pulmoner tromboendarterektomi ameliyatı ile ilgili tecrübelerimizin paylaşılması amaçlandı.

Yöntemler: Şubat 2007 - Temmuz 2018 tarihleri arasında kliniğimizde akut pulmoner emboli ve kronik tromboembolik pulmoner hipertansiyon tanılarıyla ameliyat edilen toplam 13 hasta çalışmaya dâhil edildi. Bu hastaların 9'u acil 4'ü elektif olarak ameliyata alındı. Hastalara açık kalp ameliyatı şartlarında pulmoner tromboendarterektomi cerrahi prosedürü uygulandı. Hastaların geriye dönük bilgileri hastane yazılım sisteminden elde edildi.

Bulgular: Pulmoner tromboendarterektomi uygulanan hastaların 6'sı bayan 7'si erkekti. Ortalama yaş 58 (38-71) olarak bulundu. Risk faktörü olarak 7 hastada derin ven trombozu, 3 hastada yakın zamanda geçirilmiş cerrahi, 2 hastada malinite, 5 hastada sigara kullanımı, 1 hastada behçet ve 1 hastada serebrovasküler olay öyküsü mevcuttu. Dört vaka, postoperatif 0-26 gün aralığında exitus oldu. Bunların 3'ü akut pulmoner emboli, 1'i kronik tromboembolik pulmoner hipertansiyon tanılı hastalardı.

Sonuç ve Yorum: Pulmoner tromboendarterektomi uygulanan hastaların erken dönem pulmoner arter basınçlarında belirgin düşüş izlendi. Kronik tromboembolik pulmoner hipertansiyon tanısı konan hastalar, kalıcı arteriopati gelişmeden, pulmoner tromboendarterektomi ameliyatı için cerrahi merkezlere erken dönemde yönlendirilmelidir. Akut pulmoner emboli tanısı alan hastaların cerrahiye verilme zamanlamasının önemli olduğu kanaatindeyiz. Geciken ve hipotansif şok tablosunda ameliyata alınan hastaların mortalitesi yüksek olmaktadır.

Anahtar kelimeler: Pulmoner emboli, kronik tromboembolik pulmoner hipertansiyon, pulmoner tromboendarterektomi, venöz tromboemboli. 


\title{
Our Surgical Experiences in Acute and Chronic Pulmonary Thromboembolism
}

\begin{abstract}
Introduction-Aim: If cases of pulmonary embolism are not treated, sudden death, a life-threatening acute condition or chronic thromboembolic pulmonary hypertension develops due to the organization of thrombi in the pulmonary vascular wall. In this study, it was aimed to share our experiences about pulmonary thromboendarterectomy which is not performed much more than certain centers all over the world.

Methods: A total of 13 patients with acute pulmonary embolism and chronic thromboembolic pulmonary hypertension who were operated between February 2007 and July 2018 were included in the study. Nine of these patients were operated urgently and 4 were electively operated. All patients underwent pulmonary embolectomy and endarterectomy under open heart surgery conditions. The retrospective information of the patients was obtained from the hospital software system.

Results: Of the patients who underwent pulmonary thromboendarterectomy, 6 were female and 7 were male. The mean age was 58 (38-71). As a risk factor; 7 patients had deep vein thrombosis, 3 patients had recently undergone surgery, 2 patients had malignancy, 5 patients had smoking, 1 patient had behçet and 1 patient had cerebrovascular event. 4 cases were exitus in the 0-26 day range. Three of them were acute pulmonary embolism and 1 patient with chronic thromboembolic pulmonary hypertension.

Conclusion-Comments: Early pulmonary artery pressures were significantly decreased in patients undergoing pulmonary thromboendarterectomy. Patients diagnosed with chronic thromboembolic pulmonary hypertension should be directed to surgical centers for pulmonary thromboendarterectomy without developing permanent arteriopathy. We believe that the timing of administration to patients diagnosed with acute pulmonary embolism is important. The mortality rate of patients who underwent surgery for delayed and hypotensive shock is high.
\end{abstract}

Keywords: Pulmonary embolism, chronic thromboembolic pulmonary hypertension, pulmonary thromboendarterectomy, venous thromboembolism.

\section{GíRIŞ}

Venöz tromboemboli terimi, beraberliği sık olması nedeniyle derin ven trombozu ve pulmoner emboliyi kapsayan bir isimlendirmedir. Yaklaşı 150 yıldır Virchow triadı diye bilinen; staz, koagulabilite artışı ve endotel hasarı derin ven trombozu gelişimindeki yerini korumaktadır. Özellikle ortopedik travma nedeniyle immobilize olmuş ve staz gelişmiş hastalarda, yaralanma anında veya cerrahi esnasında ekstremitenin pozisyonuna bağlı gelişen endotelyal hasarda eklenince venöz tromboz neredeyse kaçınılmaz hale gelmektedir ${ }^{1}$. Akut derin ven trombozuna bağlı \%40 oranında asemtomatik pulmoner tromboemboli (PTE) geliştiği, bu nedenle derin ven trombozu tanısı konan hastaların PTE yönünden daha iyi irdelenmesi gerektiği bildirilmektedir².
Pulmoner vasküler yatağa trombüslerin yerleşmesi sonucu ani ölüm gelişebileceği gibi yaşamı tehdit eden akut bir durum ya da ilerleyen süreç içerisinde kronik tromboembolik pulmoner hipertansiyon (KTEPH) gelişebilir. KTEPH, akut ya da tekrarlayan trombüslerin pulmoner damar duvarında organize olması sonrası küçük damarlarda gelişen arteriopatiye bağlı meydana gelir. İlerleyen süreçte kalıcı pulmoner hipertansiyon ve sağ ventrikül fonksiyon bozukluğuna neden olabilir.

Venöz tromboemboli yıllık ortalama insidansı 23-269/100.000 arasındadır ${ }^{3,4}$. KTEPH'in genel toplum insidansı $\% 0,57$, idiyopatik pulmoner tromboemboli PTE geçiren hastalarda ise \%1,5'tir5-9. KTEPH hastalarının ise \%75'inde PTE öyküsü mevcuttur ${ }^{10}$. Akut PTE'den sonra 1. ve 2. yllarda KTEPH kümülatif insidansı sırasıyla \%3,1 ve \%3,8 olarak bulunmuștur ${ }^{8}$. 
Semptomlar dispne, takipne, taşikardi, hipotansiyon, şok, kronik dönemde ise sağ kalp yetmezliği bulguları (çabuk yorulma, egzersizle gögüs ağrısı, senkop ve hemoptizi) şeklindedir.

Tanıda akciğer grafisi, ekokardiografi, ventilasyon/perfüzyon sintigrafisi, bilgisayarlı tomografi kullanılır. Multi dedektör bilgisayarlı tomografinin ventilasyon/perfüzyon sintigrafisine oranla tanıda daha değerli olduğu belirtilmektedir ${ }^{2}$. Asemptomatik PTE'li hastalarda, pulmoner anjiyografi, tanıda ve cerrahiye uygun vakaların seçilmesinde sağ kalp kateterizasyonu ile birlikte altın standart olarak yerini korumaktadır ${ }^{11}$.

Akut PTE vakaları için öncelikli tedavi antikoagülan ve trombolitik ajanlar iken, KTEPH'de medikal tedavi sınırlı olduğundan pulmoner tromboendarterektomi (PTEA) önerilen cerrahi yöntemdir.

\section{YÖNTEMLER}

Şubat 2007-Temmuz 2018 tarihleri arasında kliniğimizde akut PTE ve KTEPH tanılarılla ameliyat edilen toplam 13 hasta (8 akut PTE, 5 KTEPH) çalışmaya dâhil edildi. Bu hastaların 9'u acil 4'ü elektif olarak ameliyata alındı. Hastaların geriye dönük bilgileri hastane yazılım sisteminden elde edildi. Yerel Etik Kuruldan çalışma protokolü onayı $(2019 / 1804)$ ve her bir hastadan yazılı bilgilendirilmiş hasta onamı alındı. Çalıșma Helsinki Deklarasyonu ilkelerine uygun olarak gerçekleştirildi.

Tüm hastaların cerrahi kararı, kardiyoloji veya gögüs hastalıkları ile konsülte edilerek alındı. Akut PTE tanısı, hastaların klinik durumuna göre çoğunlukla ekokardiografi ve BT anjiografi ile konuldu. Şok tablosundaki acil cerrahi gerektiren vakalarda ise sadece ekokardiografi imajları yeterli görüldü (Resim 1). KTEPH tanısı, en az üç ay yeterli antikoagülasyona rağmen eşlik eden pulmoner hipertansiyon bulgularının varlığı, sağ kalp kateterizasyonunda ortalama pulmoner arter basincı $(\mathrm{PAB}) \geq 25 \mathrm{mmHg}$, pulmoner arterlerde (ana, lober, segmenter/subsegmenter) kronik trombüs görüntülenmesi (Resim 2 ve $3 \mathrm{AB}$ ) ve diğer pulmoner hipertansiyon yapan nedenlerin ekarte edilmesi durumunda konuldu.

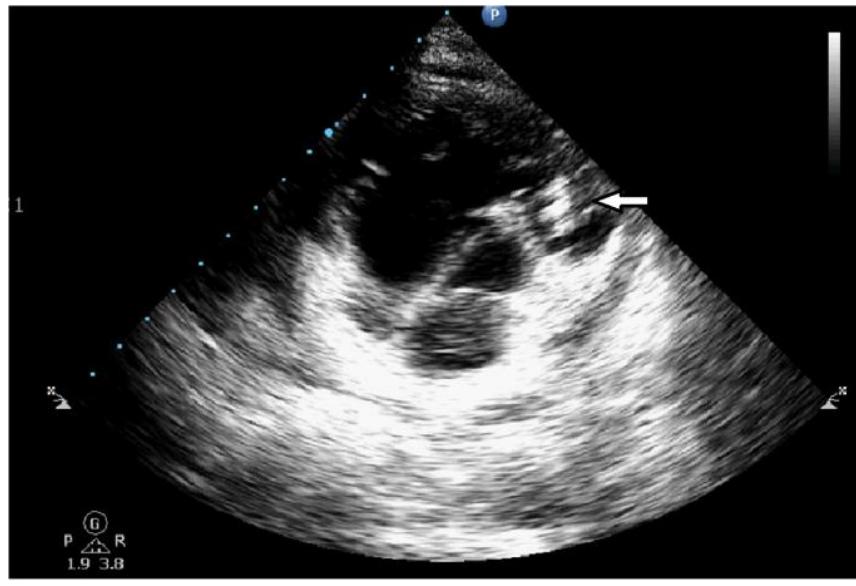

Resim 1: Pulmoner arterde ekokardiografi ile tespit edilen trombüs materyali.

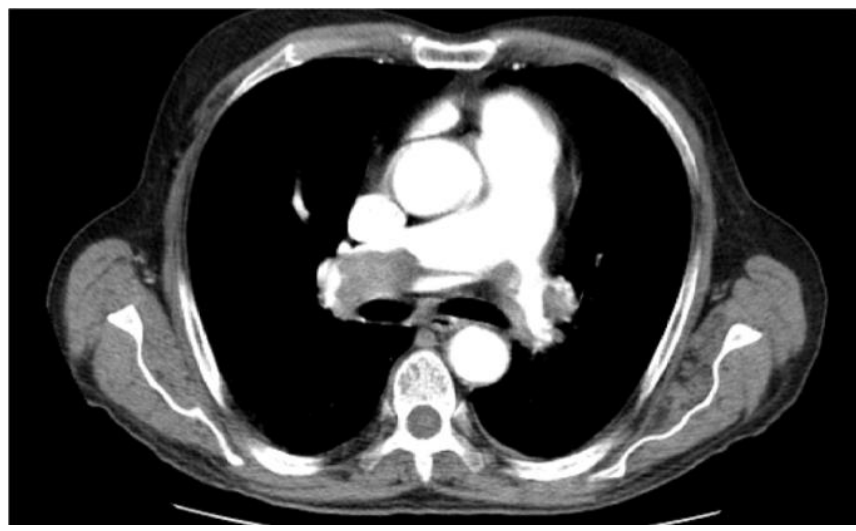

Resim 2: Her iki pulmoner arter ve segmenter dallarında BT ile tespit edilen trombüs imajı.

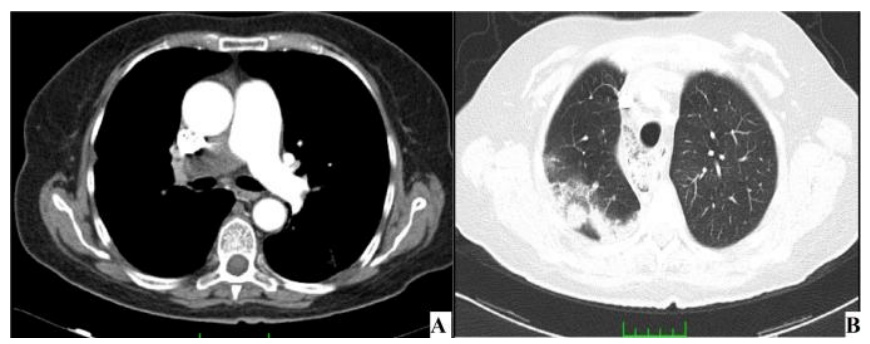

Resim 3AB: Sağ pulmoner arteri total tıkalı hastanın iki farklı pencereden BT görüntüsü. 
Operasyon; genel anestezi altında median sternotomi yapıldı, ekstrakorporeal dolaşıma geçildi, hipotermi $\left(25-32^{\circ} \mathrm{C}\right.$ aralığında) sağlandı ve kardiyak arrest ile gerçekleștirildi. Ana pulmoner arter, gerektiğinde sağ ve sol pulmoner arterler açıldı. Önce pulmoner arterlere aspirasyon uygulandı. Trombüs olduğu düşünülen akciğere dışarıdan basınç uygulanarak sıvazlandı ve çıkan trombüsler uzaklaştırıldı (Resim $4 \mathrm{AB}$ ).

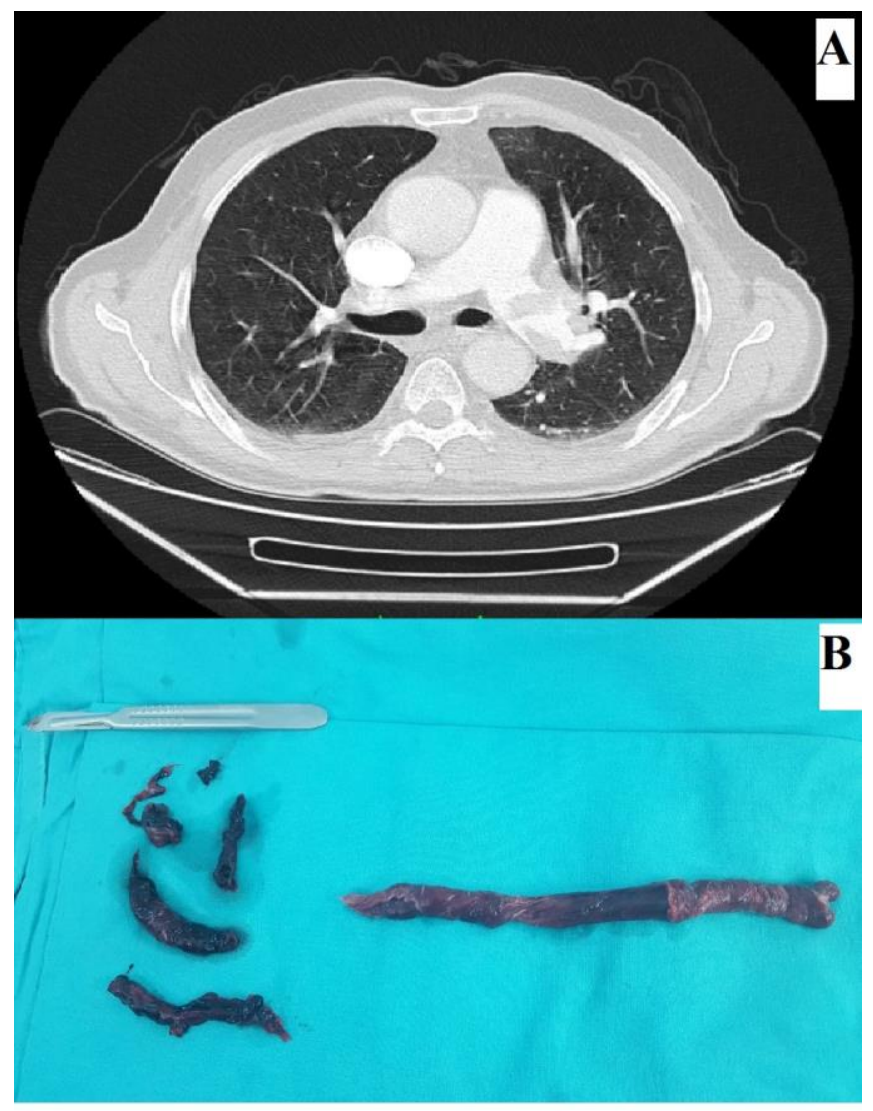

Resim 4AB: Akut pulmoner emboli tanısıyla opere edilen hastanın BT ve çıkarılan trombüs materyallerinin görüntüsü.

Organize trombüs materyalleri için, pulmoner vasküler yatağın her lobundaki segmental ve subsegmental dallar kontrol edildi. Ulaşılabilen tüm trombüs materyalleri damar bütünlüğü korunacak şekilde endarterektomi yapılarak çıkarıldı (Resim 5 ve 6). Akut pulmoner emboli ve intrakardiyak trombüs vakalarında ayrıca sağ atriotomi ve gerekirse sol atriotomi de yapılarak intrakardiyak trombüsler temizlendi. Patent foramen ovale varsa kapatıldı. Orta triküspit yetersizliğine müdahale edilmedi. Bir hastada sağ ventrikül duvarında organize trombüs mevcuttu. $\mathrm{Bu}$ hastaya sağ ventrikülotomi yapıldı ve organize trombüs ventrikül duvarıyla birlikte çıkarıldı. Perikart yama ile ventrikül duvarı onarıldı.
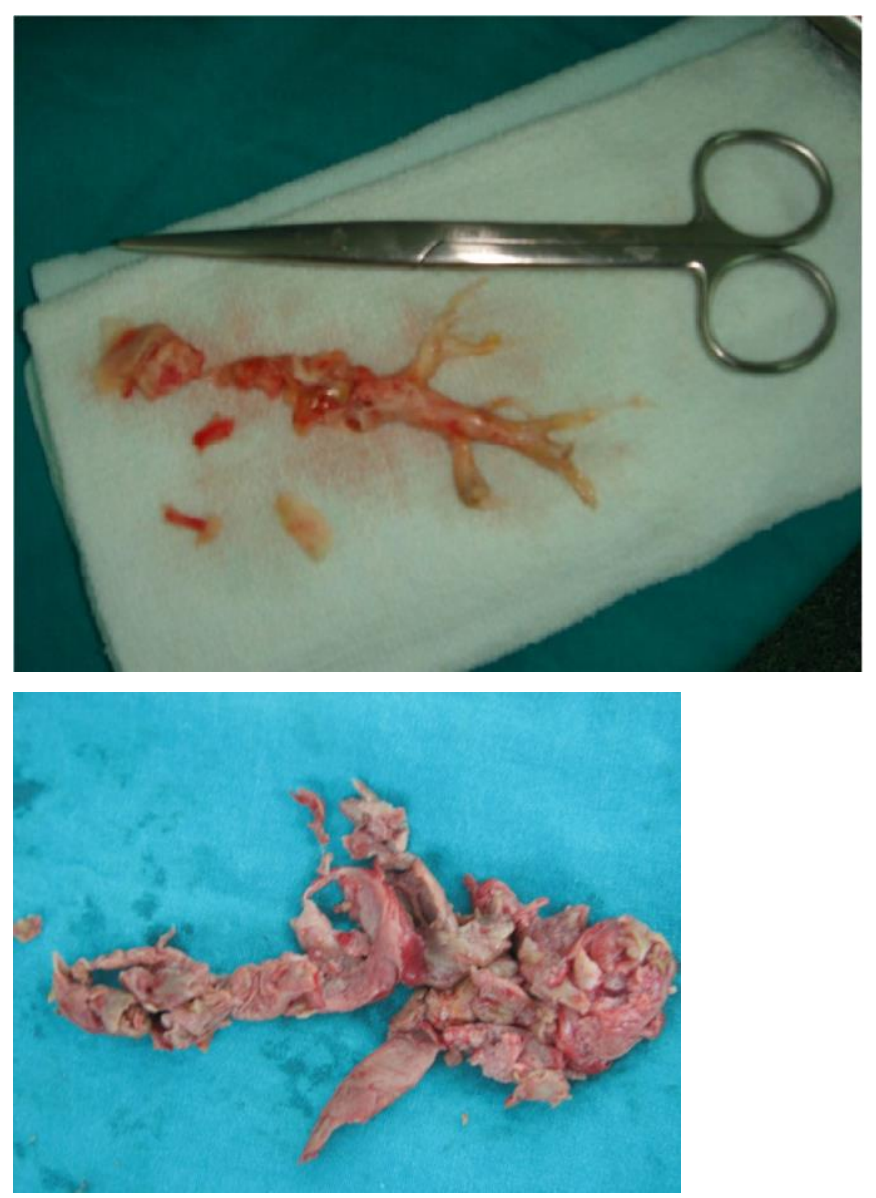

Resim 5 ve 6: Kronik tromboembolik pulmoner hipertansiyon tanısıyla opere edilen hastalardan çıkarılan endarterektomi materyalleri.

Postoperatif mekanik ventilatör desteği arteryel kan gazlarına göre ayarlandı. Ameliyat sonrası ilk 6-8 saat için 20-25 ppm'lik dozlarda inhale nitrik oksit verildi. Özellikle ilk gün aldığı-çıkardığı dengesinde negatifte kalınmaya dikkat edildi. Ekstübasyonun ardından, günde altı kez, 2,5 $\mu \mathrm{g}$ dozlarında inhale ilioprost ve bronkodilatatör nebül verildi. Düşük molekül ağırlıklı heparin, ameliyattan sonraki ilk 6-8 
saat içerisinde kiloya uygun dozda yapıldı. Coumadin 24-72 saat içinde başlandı ve INR yaklaşık 2,5-3 Aralığında olacak şekilde ayarlandl. Kontrol transtorasik ekokardiyografi, hastaların hastaneden taburcu olduğu gün bakıldı. Hastalara postoperatif 1'inci hafta ve 1'inci ayda poliklinik kontrolü yapıldı. Operatif mortalite, hastanede veya ameliyattan sonraki ilk 30 gün içinde gerçekleşen ölüm olarak tanımlandı.

\section{BULGULAR}

PTEA uygulanan 13 hastanın 6'sı bayan 7'si erkekti. Ortalama yaş 58 (38-71) olarak bulundu. Akut PTE vakalarının ameliyat öncesi semptomları 0-7 gün arasında değişirken, KTEPH vakalarının şikâyetleri ise 3-16 ay arasında değişmekteydi. 4 hasta aynı gün, 5 hasta postoperatif 1. Gün ekstübe edildi. Hastalar postoperatif ortalama 10'uncu (7-15) günde taburcu oldu.

Hastaların öz geçmişlerinde PTE risk faktörü olarak; 7' sinde derin ven trombozu, 3'ünde yakın zamanda geçirilmiş cerrahi (kolesistektomi, disk hernisi, myomektomi), 2'sinde malinite (larinks ve meme CA), 5 hastada sigara kullanımı, 1 hastada behçet ve 1 hastada serebrovasküler olay öyküsü mevcuttu.

Toplam 4 vaka postoperatif 0-26 gün aralığında exitus oldu. Bunların 3'ü akut PTE, 1'i KTEPH hastası idi. KTEPH vakası, kronik zemin üzerine akut emboli atağ geçiren ve trombolitik tedaviye rağmen hemodinamisi düzelmeyen bir hastaydl. Acil olarak hipotansif şok tablosunda operasyona alındı ancak postoperatif 2'nci gün kaybedildi.

Pnömoni, sepsis nedeniyle postoperatif 26'ncı gün kaybedilen bir hastanın bronkoalveoler lavaj kültüründe Acinetobacter Baumanni, kan kültüründe Staphylokokkus Hominis üredi. Hastalara ait daha detaylı bilgiler Tablo 1'de verilmiştir.

\section{TARTIŞMA}

PTEA, pulmoner arterlerdeki çözülmemiş tromboembolik materyalleri çlkarmak için yapılan ve kanlanmayan ya da az kanlanan akciğer bölgelerine yeniden kan götürmeyi amaçlayan komplike bir cerrahi işlemdir. Pulmoner embolektomiden farkl, trombüs materyalinin organize olması nedeniyle endarterektomi gerekebilmesidir. Cerrahi sonrası pulmoner vasküler rezistansta düşme ve kardiyak fonksiyonlarda iyileşme beklenir. Kalıcı pulmoner hipertansiyon gelişen hastalar akciğer nakli adayıdır.

VTE tanısı konan hastalarda medikal tedaviye hızlı ve etkin başlanırsa operasyona gidecek pulmoner emboli vakalarının azalacağı belirtilmektedir ${ }^{12}$. Akut PTE'de öncelikli tedavi antikoagülan ve trombolitik ajanların kullanılmasıdır. Ancak masif PTE olgularında, kontrendikasyon nedeniyle trombolitik tedaviye engel varsa veya trombolitik tedaviye cevap alınamiyorsa, ya da trombolitik tedavi beklenilemeyecek kadar kötü bir hemodinamik durum söz konusu ise, cerrahi ya da kateter embolektomi yapılmalıdır13,14. Sağ kalp boşluklarında trombüs saptandığında ve patent foramen ovaleden kaynaklanan paradoksal emboli vakalarında cerrahi embolektomi ilk tedavi seçeneği olarak belirtilmiştir ${ }^{13-14}$. Trombolitik tedavi, sistemik olarak verilebildiği gibi kateter aracılığı ile lezyon bölgesine de uygulanabilir. Ancak yeterli kanıt olmadığı için 2016 ACCP rehberinde kateter aracılı tromboliz önerilmemektedir ${ }^{15}$.

Akut PTE hastalarında öncelikle medikal tedavi verilip, tedaviye yanıt alınamadığı takdirde ilgili kliniklerin ortak görüşüyle cerrahi kararı alınmaktadır. Tedaviye yanıt alınamayıp cerrahiye verilen hastalar çoğunlukla genel durumu bozuk ve hipotansif şok tablosundadır. Cerrahi kararını verme sürecinde geçirilen zaman önem arz eder. 
Işık M., Tanyeli Ö., Dereli Y., Ege E., Görmüş N.

Tablo I: Hastalara ait genel veriler ve ekokardiografi bulguları.

\begin{tabular}{|c|c|c|c|c|c|}
\hline Hasta & Tanı & $\begin{array}{l}\text { Cinsiyet } \\
\text { ve yaş }\end{array}$ & Özgeçmiş & $\begin{array}{l}\text { Preoperatif } \\
\text { durum }\end{array}$ & Ekokardiografi \\
\hline Hasta 1 & Akut PE & $\mathrm{E} / 71$ & Bilinmiyor & Acil, GD kötü, entübe & SAT, PAT, PAB1: 45 \\
\hline Hasta 2 & Akut PE & $\mathrm{E} / 67$ & DVT, Sigara Malinite & $\begin{array}{l}\text { Acil, GD kötü hipotansif } \\
\text { şokta }\end{array}$ & SAT, PAT, PAB1: 40 \\
\hline Hasta 3 & Akut PE & $\mathrm{K} / 46$ & SVO, HT, Sigara & Acil, GD orta & SAT, PAT, PAB1:27, PAB2:20 \\
\hline Hasta 4 & Akut PE & E/61 & Sigara & $\begin{array}{l}\text { Acil, GD kötü, hipotansif } \\
\text { șokta }\end{array}$ & Her iki atriumda trombüs, PFO \\
\hline Hasta 5 & Akut PE & $\mathrm{K} / 41$ & Malinite, Behçet & Acil, GD orta & SAT, PAB1: 40 PAB2: 30 \\
\hline Hasta 6 & Akut PE & $\mathrm{E} / 60$ & DVT & Acil, GD orta & SAT, PAB1: 25 PAB2: 20 \\
\hline Hasta 7 & Akut PE & $\mathrm{E} / 58$ & Sigara & Acil, GD orta & SAT, PAB1: 30 PAB2: 20 \\
\hline Hasta 8 & Akut PE & $\mathrm{K} / 60$ & DVT, HT & Acil, GD kötü & SAT, PAB1: 35 PAB2: 25 \\
\hline Hasta 9 & КТЕРН & $\mathrm{E} / 71$ & $\begin{array}{l}\text { DVT, Pulmoner } \\
\text { emboli, sigara, HT }\end{array}$ & $\begin{array}{l}\text { Acil, GD kötü, Trombolitik } \\
\text { verildi }\end{array}$ & Sağ boşluklar geniş PAB1: 60 \\
\hline Hasta 10 & KTEPH & $\mathrm{K} / 51$ & GC & Elektif, GD orta & Sağ ventrikülde trombüs PAB1:70, PAB2:40 \\
\hline Hasta 11 & КTEPH & $\mathrm{K} / 65$ & DVT, HT & Elektif, GD orta & Sağ boşluklar geniş PAB1:50, PAB2:30 \\
\hline Hasta 12 & KTEPH & $\mathrm{K} / 38$ & Astım, DVT, GC & Elektif, GD orta & Sağ boşluklar geniş PAB1:60, PAB2:33 \\
\hline Hasta 13 & KTEPH & $\mathrm{E} / 67$ & DVT, GC, HT & Elektif, GD orta & Sağ boşluklar geniș, PAB1:85, PAB2:60 \\
\hline
\end{tabular}

PE: Pulmoner emboli, E: Erkek, K: Kadın, GD: Genel durum, SAT: Sağ atriumda trombüs, PAT: Pulmoner arterde trombüs, PAB1: Preop pulmoner arter basıncı, PAB2: Postop pulmoner arter basıncı, DVT: Derin ven trombozu, SVO: Serebrovasküler olay, HT: Hipertansiyon, PFO: Patent foramen ovale, KTEPH: Kronik tromboembolik pulmoner hipertansiyon, GC: Geçirilmiş cerrahi.

Hastaların şok tablosunda kalma süresi uzadıkça ventrikül fonksiyonları daha da bozulur ve pozitif inotrop ihtiyacı artar. Ayrıca preoperatif trombolitik ve antikoagülan tedavi verildiği için, postoperatif kanama kontrolünde de sıkıntılar yaşanır. Bütün bunlar cerrahi başarıyı olumsuz etkileyen faktörlerdir. Cerrahiye aldığımız 8 Akut PTE vakasının 3'ü genel durumu bozulmuş ve şok tablosundaki hastalardı. Bu 3 hastanın 2'si, ameliyat sonrası aynı gün kalp ve akciğer yetmezliği tanısıyla kaybedildi. Diğer bir hasta ise postoperatif 26 . Gün, akciğer ödemi sonrası pnömoni-sepsis gelişmesi nedeniyle eksitus oldu.

1144 merkez ve 1075 hasta ile yapılan geniş serili bir çalışmada, sadece 310 hastanede yılda en az 1 (genel ortalama 0,42 \pm 1 vaka/yll/merkez) akut pulmoner embolektomi ameliyatı yapıldığı raporlanmıștır. Yaș, kardiyojenik şok, kardiyopulmoner bypass süresi, kronik akciğer hastalığı, preoperatif arrest, serebral olay varlığ gibi farklı hasta gruplarında mortalitenin çok değişken olduğu belirtilmektedir ${ }^{16}$.

KTEPH tanil uygun hastalarda potansiyel küratif tedavi yöntemi PTEA'dır ${ }^{17}$. Genel destek tedavisi sonrası beş yıllık yaşam $\mathrm{PAB}<40$ mmHg olan vakalarda \%30, $\mathrm{PAB}>50 \mathrm{mmHg}$ olan vakalarda \%10 olarak bulunmuştur ${ }^{18,19}$. Medikal tedavi için kullanılan birçok periferik arter hastalığına yönelik ilaçlardan olumlu sonuç alınamamıştır ${ }^{20,21}$. Yeni üretilen çözünür guanilat siklaz stimülatörü riociguat ile yapılan çalışmalarda, fonksiyonel kapasitenin iyileștiği, 
hemodinamik bulguların düzeldiği ve 6 dakika yürüme mesafesinin arttığı belirlenmiștir ${ }^{22}$.

KTEPH için cerrahi mortalite merkezlerin deneyimine göre \%6-24 arasında değişmektedir ${ }^{17,23,24}$. Ameliyat ettiğimiz KTEPH tanılı 5 hastadan biri postoperatif 2. Gün kaybedildi. Bu hasta 2 yıldır KTEPH tanısıyla antikoagülan tedavi alırken yeni bir atakla hastanemize başvurdu. Trombolitik tedaviye rağmen genel durumunun bozulması üzerine acil ameliyata alındı.

PTEA'nın en önemli postoperatif komplikasyonları kalıcı pulmoner hipertansiyon ve reperfüzyon akciğer ödemidir. PTEA sonrası hastaların \%5-33'ünde pulmoner hipertansiyon (PAB $>25 \mathrm{mmHg}$ ) kalıcı olabilir ${ }^{25-}$ 27. Bunun nedenleri yetersiz endarterektomi, yeniden trombüs oluşması, erişilemeyen distal trombüs varlığı ve gelişmiş olan kalıcı arteriopatidir. Reperfüzyon akciğer ödemi insidansı yaklaşık \%10-15 olarak bildirilmiştir ${ }^{28}$. Sıvı kısıtlaması, agresif olmayan mekanik ventilasyon ve pompa çıkışı düşük pozitif inotrop ihtiyacının, reperfüzyon akciğer ödemi ve sağ kalp yetmezliği sıklığını düşürdüğü belirtilmiştir ${ }^{28}$. Diğer postoperatif komplikasyonlar hastane kaynaklı pnömoni, akciğer yatağına kanama, hemoptizi, endarterektomi yapılan bölgede rüptür sayılabilir.

$\mathrm{Bu}$ çalışmada postoperatif gelişen komplikasyonlar şunlardı: Dört hastada reperfüzyon akciğer ödemi meydana geldi. Bunlardan birinde akciğer ödemi sonrası pnömoni gelişti. İki hastada PTEA esnasında pulmoner arter damar duvarı bütünlügü bozuldu ve biri primer tamir edilirken diğerine perikart yama uygulandl.

Hemodinamisi ve oksijen değerleri aşırı derecede kötü olan hastalarda ekstrakorporeal membran oksijenasyon (ECMO) desteği fayda sağlayabilir. Veno-arteriyel ECMO, hemodinamik destek ihtiyacı olan vakalar da, veno-venöz ECMO ise hipoksik durumlarda kullanılabilir. Cerrahi öncesi hastayı stabilize etmek için veno-arteryel ECMO kullanımının olumlu sonuçları bildirilmektedir ${ }^{29}$. Ameliyat ettiğimiz hastalardan birinde pompa çıkışı veno-arteriyel ECMO kullanıldı ancak hasta kaybedildi.

Hastaların preoperatif bakılan transtorasik ekokardiografi PAB'ları ile taburculuğu sırasında bakılan PAB değerleri karşılaştırması şöyle idi: Akut PTE için preoperatif ortalama PAB: $31,4 \quad(25-40) \mathrm{mmHg}$, postoperatif ortalama PAB: 23 (20-30) $\mathrm{mmHg}$, ortalama düşüş \%26,8 idi. KTEPH için preoperatif ortalama PAB: 66,2 (50-85) $\mathrm{mmHg}$, postoperatif ortalama PAB: 40,7 (30-60) mmHg, ortalama düşüş \%38,5 olarak bulundu.

Fonksiyonel triküspid yetersizliği (TY), hastaların \%70'inde görülmektedir. Başarılı PTEA'dan sonra pulmoner arter basincinda büyük oranda düşme beklendiğinden, PTEA ile eş zamanlı triküspid anüloplasti yapılması önerilmemektedir ${ }^{30,31}$. Başka bir çalışmada PTEA ameliyatından sonra bile, hastaların\%30'unda rezidüel pulmoner hipertansiyon kaldığı ve buna bağlı olarak kalıcı TY geliştiği bildirilmiștir ${ }^{20}$. Preoperatif beș hastamızda orta, bir hastada ise ciddi fonksiyonel TY tespit edildi ve hiçbirine cerrahi müdahale yapılmadı. $\mathrm{Bu}$ hastalardan üçü taburcu edildi. Taburculuk esnasinda bakılan ekokardiografilerde hastaların üçünün de TY'sinin gerilediği görüldü.

Pulmoner hipertansiyon varlığında să̆ ventrikül fonksiyonlarını iyileștirmek amacıyla postoperatif NO ve ilioprost (prostasiklin analoğu) kullanımının faydalı olduğunu belirten çalışmalar mevcuttur ${ }^{17}$. Bizde 4 PAB'$^{\prime}$ yüksek hastada NO, ilioprost ve milrinon kullandık. Ancak etkinliği konusunda görüş belirtecek düzeyde bir tecrübeye sahip değiliz.

Sonuç olarak, PTEA uygulanan hastaların erken dönem PAB'larında belirgin düşüş izlendi. KTEPH tanisı konan hastalar, cerrahi mortalitesi kabul edilebilir düzeyde olan PTEA 
için cerrahi merkezlere erken dönemde yönlendirilmelidir. Aksi takdirde küçük damarlarda arteriopati gelişen hastalarda çok fazla alternatif tedavi seçeneği bulunmamaktadır. Akut pulmoner emboli tanısı alan hastalarin cerrahiye verilme zamanlamasının önemli olduğu kanaatindeyiz. Geciken ve hipotansif şok tablosunda ameliyata alınan hastaların mortalitesi yüksek olmaktadır.

Çıkar Çatışması Beyanı: Yazarlar çıar çatışması olmadığını bildirmişlerdir.

Finansal Destek: Bu çalıșma her hangi bir fon tarafından desteklenmemiştir.

Declaration of Conflicting Interests: Theau thorsdeclare that theyhavenoconflict ofinterest.

Financial Disclosure: No financial support was received.

\section{KAYNAKLAR}

1. Erkoçak ÖF, Erkoçak R, Kara İ, et al. Ortopedik Cerrahide İntraoperatif Masif Pulmoner Emboli. Selçuk Tıp Dergisi. 2010; 26: 150-2.

2. Yücedağ E, Uysal A, Burma O, et al. Comparison of ventilation/perfusion scintigraphy and multi-detector computerized tomography in diagnosis of asymptomatic pulmonary embolism after deep vein thrombosis. Dicle Med J. 2014; 41: 179-86.

3. Wong P, Baglin T. Epidemiology, risk factors and sequelae of venous thromboembolism. Phlebology. 2012; 2: 2-11.

4. Spencer FA, Emery C, Joffe SW, et al. Incidence rates, clinical profile, and outcomes of patients with venous thromboembolism. The Worcester VTE study. J Thromb Thrombolysis. 2009; 28: 401-9.

5. Tapson VF, Humbert M. Incidence and prevalence of chronic thromboembolic pulmonary hypertension:from acute to chronic pulmonary embolism. Proc Am Thorac Soc. 2006; 3: 564-7.

6. Auger WR, Kim NH, Kerr KM, et al. Chronic thromboembolic pulmonary hypertension. Clin Chest Med. 2007; 28: 255-69.

7. Ribeiro A, Lindmarker P, Johnsson $\mathrm{H}$, et al. Pulmonary embolism: one year follow-up with echocardiographic
Doppler and five year survival analysis. Circulation. 1999; 99: 1325-30.

8. Klok F, van Kralingen KW, van Dijk APJ, et al. Prospective cardiopulmonary screening program to detect chronic thromboembolic pulmonary hypertension in patients after acute pulmonary embolism. Haematologica. 2010; 95: 970-5.

9. Korkmaz A, Ozlu T, Ozsu S, et al. Long-term outcomes in acute pulmonary thromboembolism: the incidence of chronic thromboembolic pulmonary hypertension and associated risk factors. Clin Appl Thromb Hemost. 2012; 18: 281-8.

10. Delcroix M. Choronic post-embolic pulmonary hypertension. Eur Respir Rev. 2013; 22: 258-64.

11. Bozlar U, Gaughen JR, Nambiar AP, Hagspiel KD. Imaging diagnosis of acute pulmonary embolism. Expert Rev Cardiovasc Ther. 2007; 5: 519-29.

12. Velioğlu Y, Erkut B, Ünlü Y, et al. Deep Venous Thrombosis and Treatment Procedures (Experience with 505 Patients). Turk J Vasc Surg. 2006; 15: 001-13.

13. Torbicki A, Perrier A, Konstantinides SV, et al. Guidelines on the diagnosis and management of acute pulmonary embolism: The Task Force for the Diagnosis and Management of Acute Pulmonary Embolism of the European Society of Cardiology (ESC). Eur Heart J. 2008; 29: 2276-315.

14. Kearon C, Akl EA, Comerota AJ, et al. Antithrombotic Therapy for VTE Disease: Antithrombotic Therapy and Prevention of Thrombosis, 9th ed: American College of Chest Physicians Evidence-Based Clinical Practice Guidelines. Chest. 2012; 141(Suppl 2): e419S-e94S.

15. Kearon C, Elie Akl, Ornelas J, et al. Antithrombotic Therapy for VTE Disease: CHEST Guideline and Expert Panel Report. Chest. 2016; 149: 315-52.

16. Kon ZN, Pasrija C, Bittle GJ, et al. The Incidence and Outcomes of Surgical Pulmonary Embolectomy in North America. Ann Thorac Surg. 2019; 107: 1401-8.

17. Yıldızeli B, Taş S, Yanartaş M, et al. Pulmonary endarterectomy for chronic thrombo-embolic pulmonary hypertension: an institutional experience. Eur J Cardiothorac Surg. 2013; 44: 219-27.

18. Riedel M, Stanek V, Widimsky J, Prerovsky I. Longterm follow-up of patients with pulmonary thromboembolism. Late prognosis and evolution of hemodynamic and respiratory

data. Chest. 1982; 81: 151-8. 
19. Lewczuk J, Piszko P, Jagas J, et al. Prognostic factors in medically treated patients with chronic pulmonary embolism. Chest. 2001; 119: 818-23.

20. Madani MM, Auger WR, Pretorius V, et al. Pulmonary endarterectomy: recent changes in a single institution's experience of more than 2700 patient. Ann Thorac Surg. 2012; 94: 97-103.

21. Dartevelle P, Fadel E, Mussot S, et al. Chronic thromboembolic pulmonary hypertension. Eur Respir J. 2004; 23: 637-48.

22. Ghofrani HA, D'Armini A, Grimminger F, et al. Riociguat for the treatment of chronic thromboembolic pulmonary hypertension. N Engl J Med. 2013; 369: 31929.

23. Oh SJ, Bok JS, Hwang HY, Kim KH, Kim KB. Clinical out- comes of thromboendarterectomy for chronic thromboembolic pulmonary hypertension: 12-year experience. Korean J Thorac Cardiovasc Surg. 2013; 46: 41-8.

24. Mellemkjaer S, Ilkjaer LB, Klaaborg KE, et al. Pulmonary endarterectomy for chronic thromboembolic pulmonary hypertension. Ten years experience in Denmark. Scand Cardiovasc J. 2006; 40: 49-53.

25. Freed DH, Thomson BM, Berman M, et al. Survival after pulmonary thromboendarterectomy: effect of residual pulmonary hypertension. J Thorac Cardiovasc Surg. 2011; 141: 383-7.
26. Yanartaş M, Acar RD, Yıldızeli B. The Pulmonary Thromboendarterectomy Increases Gradually All Over the World; Review. Koşuyolu Heart Journal. 2016; 19: 184-90.

27. Hoeper MM, Mayer E, Simonneau G, Rubin LJ. Chronic thromboembolic pulmonary hypertension. Circulation. 2006; 113: 2011-20.

28. Mares P, Gilbert TB, Tschernko EM, et all. Pulmonary artery thromboendarterectomy: a comparison of two different postoperative treatment strategies. Anesth Analg. 2000; 90: 267-73.

29. Pasrija C, Kronfli A, George P, et al. Utilization of veno-arterial extracorporeal membrane oxygenation for massive pulmonary embolism. Ann Thorac Surg. 2018; 105: 498-504.

30. Menzel T, Kramm T, Wagner S, et al. Improvement of tricuspid regurgitation after pulmonary thromboendarterectomy. Ann Thorac Surg. 2002; 73: 756-61.

31. Sadeghi HM, Kimura BJ, Raisinghani A, et al. Does lowering pulmonary arterial pressure eliminate severe functional tricuspid regurgitation? Insights from pulmonary thromboendarterectomy. J Am Coll Cardiol. 2004; 44: 126-32. 